2016-12-12

\title{
Suicide in an ageing UK population: problems and prevention
}

\author{
Hodge, Gary
}

http://hdl.handle.net/10026.1/18834

10.1108/qaoa-05-2015-0022

Quality in Ageing and Older Adults

Emerald

All content in PEARL is protected by copyright law. Author manuscripts are made available in accordance with publisher policies. Please cite only the published version using the details provided on the item record or document. In the absence of an open licence (e.g. Creative Commons), permissions for further reuse of content should be sought from the publisher or author. 


\title{
Suicide in an ageing UK population: problems and prevention
}

\begin{abstract}
Purpose - Suicide can be an emotive, and at times, controversial subject. The purpose of this paper is to reflect on the social, health, personal, and cultural issues that can arise in later life and the potential reasons for suicide. It will analyse already recognised risk factors of suicide in older adults and focus on improving knowledge about the social meaning and causation of suicide for older people. It will also consider suicide prevention policies, their practice implications, and whether they are successful in protecting this potentially vulnerable cohort.
\end{abstract}

Design/methodology/approach - A synopsis of available literature in the form of a general review paper of suicide of older adults.

Findings - There is evidence that the ageing process often leads to a set of co-morbidities and a complex and diverse set of individual challenges. This in turn equates to an increased risk of suicide. There is no easy answer to why there is evidence of a growing number of older adults deciding that suicide is there only option, and even fewer suggestions on how to manage this risk.

Social implications - The entry of the "baby boom" generation into retirement will lead to the potential of an increase in both suicide risk factors and older adults completing suicide. This is on the background of a demographic surge which is likely to place additional pressures on already under-resourced, and undervalued, statutory and non-statutory services.

Originality/value - A literature search found very little information regarding older adults and suicide risk, assessment, treatment or prevention.

Keywords Suicide, Mental health, Health, Depression, Dementia, Inequality

Paper type General review

\section{Introduction}

This paper will seek to explore suicide and suicide prevention in an ageing population in the UK. It will include a reflection of the social and cultural background and reasons for suicide of older adults. The paper will consider these factors from a biopsychosocial and holistic perspective, exploring the aetiology of ageing, and its social impact on emotional wellbeing. It will also consider the demographic changes in population and the impact on suicide rates in the UK.

\section{Background}

The post-Second World War "baby boom" generation has now started to reach retirement age, with the "baby boom" generation predicted to boost our ageing population in future decades (Bayliss and Sly, 2010). For the first time in history, there are 11 million people aged 65 or over in the UK and this is projected to increase in the next 25 years to more than 16.4 million (Age UK, 2014). In 2013, there were 6,708 recorded suicides in the UK and Republic of Ireland, with statistical increases in the mid age groups and over $85 \mathrm{~s}$ (Samaritans, 2015).

Despite the fact that suicide and its prevention continues to be a priority area for healthcare services in the UK, suicide of older adults remains a neglected subject, receiving little interest or research attention (Cattell, 2000; Gavrielatos et al., 2006) The number of suicides 
and the prevalence of suicidal tendencies are rising faster among older men than in any other age group (Nugent, 2012). Suicide among men aged over 55 has risen by 12 per cent over the past decade, whilst suicides by men aged below 34, have dropped by 30 per cent (Office for National Statistics, 2013). Over one thousand men aged 50 plus end their own lives every year in England and Wales (Mental Health Foundation, 2014). Men aged 75 and over have the highest rate of suicide among older adults, although these figures have been decreasing slightly in recent years; it is now predicted to increase (Department of Health, 2012a). The Office for National Statistics (2012) states that one of the highest increases they have seen is in suicide rates amongst women aged 75 plus. Murphy et al. (2012) found that the risk of suicide among older adults who self-harmed was three times greater than the relative risk of suicide among younger adults. the most common method of self-harm of older adults was through self-poisoning (88 per cent), with 1.5 per cent of those selfharming, dying by suicide within a year. There are multi-faceted and interrelated factors associated with why there is an increased risk of a completed suicide in an older person; one of which could be robust suicide planning, alongside a strong determination to die (Beeston, 2006). Older adults are less likely than younger people to talk about suicide, but more likely to carry it out (Help the Aged, 2004).

\section{Literature review}

A literature search found very little information regarding older adults and suicide risk, assessment, treatment, or prevention. In 2002 the National Suicide Prevention Strategy recognised this cohort as a high-risk group (Her Majesty's Government and Department of Health, 2002), evidencing that this is only going to worsen in coming decades. The causes for the increase in suicidality of older adults does not appear to be answered at present, but many theories exist. Manthorpe and Iliffe (2010) found that although a majority of older people who completed suicide had major depression, suicide of older adults is often due to a combination of personal factors and physical co-morbidities. Statistical increases also would appear to correlate with the current "baby boom generation" (Scogin, 2009). For older adults, depression, dementia, poor physical health, poverty, and social isolation, can all increase the risk of suicide (Shah, 2013). Alcohol dependency is also common among older adults who attempt suicide (Department of Health, 2012a).

\section{Depression}

A mental health need is present in almost 40 per cent of older adults visiting their GP, and a staggering 60 per cent of those in care homes (Anderson et al., 2009). Mental health difficulties are significantly associated with higher mortality rates (Graham et al., 2011). For every one million older adults with depression, only 150,000 receive treatment even though its presence increases the risk of suicide (Hawton and Harriss, 2006; Anderson et al., 2009). Black and minority ethnic (BME) groups make up a significant number of those with depression, and poor treatment outcomes (Shah, 2013). The National Institute for Health and Clinical Excellence (NICE) (2004) guidelines on the management of depression in primary and secondary care report that primary care is responsible for guiding much of its early treatment, but depression is often missed due to co-morbid physical symptoms taking precedence. Laidlaw et al. (2008) emphasise the importance of early detection of "subsyndromal symptoms" in older adults, as the development of a severe depression is likely to lead to very poor outcomes. It is well-known that when depression is treated, quality of life also improves, alongside co-morbid physical wellbeing (National Institute for 
Mental Health in England, 2005). This, in turn, leads to a marked reduction in suicidal ideation of older adults (Bruce et al., 2004). However, Almeida et al. (2012) argue that this assumption is unproven, and too simplified, given the complexity of causes of suicidal ideation in this particular population.

Since depression in later life is the major risk factor for suicide, it is often undervalued and lacking in attention (Hawton and Harriss, 2006, Age Concern, 2008). This is significant with 90 per cent of elderly suicide victims reported to have had depression (Shah, 2013). Szanto et al. (2001) argue that suicidal ideation is a not a definitive feature of mood disorder, and in older adults, its presence is also not clearly linked to the severity of the depression. Nonetheless, in most cases of depression, the same risk and protective factors exist (Fiske et al., 2009).

\section{Dementia}

Study findings are mixed regarding the role of dementia itself as a risk factor for suicide, while there is sample evidence that dementia is a predictor of suicide given the prevalence of dementia among older adults, particularly the "oldest" of old. Erlangsen et al. (2008) found that people over 70 years old with a diagnosis of dementia were three times more at risk of suicide than those without a dementia diagnosis. Purandare et al. (2009), from their nine-year study, which considered suicide risk in people diagnosed with dementia, found a low prevalence of risk of suicide in the first year of a dementia diagnosis, but a higher risk when the patient experienced a loss of ability to complete activities of daily living, while retaining some insight. Some studies, however, found no association between those with cognitive impairment and suicide (Turvey et al., 2002). Suicide in dementia also raises an ethical dilemma in that many people believe suicide is an acceptable course of action for those diagnosed (Powell, 2014). Mitchell (2008) argues that talk of accepting suicide (including assisted suicide and euthanasia) "as a way out" for people diagnosed with dementia, is based on misconceptions and ignorance, and that future discussion should focus on the development of advanced decisions. Sontheimer (2008) disagrees, stating that any advance decision referring to suicide, including assisted suicide, will only complicate matters and medical decision-making; care should only ever be withdrawn when recovery is futile.

\section{Poor physical health}

TheWorld Health Organization (1998) describes health as "a state of complete physical, mental, and social well-being, and not merely the absence of disease or infirmity". In most countries, including the UK, life expectancy is increasing, with the fastest growing group being women, and those aged 85 and older (International Federation of Social Workers, 2012). An increase in life expectancy however leads to a longer exposure to risk factors to physical health over time, and in turn, comorbidity (Spijker and Maclnnes, 2013). The "oldest" of old are more likely to face complex physical, social, and emotional problems often leading to ongoing mental health difficulties (Department of Health, 2014a). The World Health Organization (2007) have recognised for some time now that the stress of disease and disability can lead to mental health difficulties; likewise, mental health difficulties can magnify physical health problems, or slow recovery from disease and disability. All of these problems as previously discussed can lead to significant suicidal ideation and the risk of suicide. Significant mental and physical health problems also arise 
for the carers, particularly elderly carers meeting complex caregiving needs of frail or disabled relatives. This is a particular problem for the growing ageing population as rates of life limiting long-term illness increases considerably with age. In 2008, 47 per cent of people aged over 75 reported a long-term illness that somehow limited their activities, compared to 33 per cent of 65-74-year olds and 22 per cent of 45-64-year olds (Parekh et al., 2010). Estimates report that between 40 and 70 per cent of carers have clinical features of depression, placing them at risk of coexisting anxiety disorders, substance abuse, and suicide (Spector and Tampi, 2005). A pilot study looking at suicide risk in carers of people with dementia found 26 per cent of carers had contemplated suicide more than once in the year before the study, and almost 30 per cent said they were likely to attempt suicide in the future (O'Dwyer et al., 2013).

\section{Poverty}

The risk of mental illness for someone in the poorest fifth of the population is around twice the average of the whole population (Parekh et al. 2010). Poverty not only increases the risk of mental illness, it in turn increases the risk of suicide. Suicide rates in the most deprived areas in England and Wales were more than double those in the least deprived areas (Dunnell, 2008). Recent UK governmental protections over pensions, however, have led to the proportion of pensioners in low-income households halving over the last decade, with only 14 per cent of pensioners considered to be living in poverty (Department for Work and Pensions, 2013). This is not reflected in Inner London however, where there is a much higher proportion (22 per cent $1 / 4190,000$ ) of pensioners in low-income households groups (Aldridge et al., 2013). Poverty is difficult to measure in purely material terms and can come in many forms, including fuel poverty. Each year, around 20,000 more people aged 65 or over, die across all UK regions in winter months compared to other months (Palmer, 2010). Fuel poverty is the inability to meet the cost of water, heating, cooking, lights, and the running of appliances with people defined as fuel poor if spending in excess of 10 per cent of their household income on fuel which is used to achieve a satisfactory standard of warmth (Office of the First Minister and Deputy First Minister, 2013). Fuel poverty is an increasing issue for older adults across the UK. There are around 1.14 million older adults in England (Department of Energy \& Climate Change, 2013) and 61.7 per cent of retired households in Northern Ireland in 2011 living in fuel poverty, compared to 38.2 per cent in 2001. The UK government has been making efforts to address this. In 2011Winter Fuel Allowance cost 2.7 billion pound helping over 12.3 million older adults (Kennedy, 2013). Fuel poverty and living in a cold home have a direct impact on adverse health issues, including respiratory problems and depression, alongside wider social impacts, such as social isolation (Age UK, 2014). There is very little evidence to prove fuel poverty is directly related to risk for suicide. However there is a strong correlation between cold housing and poor physical and mental health (Royal College of Nursing, 2012), which are predictors of suicide risk.

\section{Social isolation}

Loneliness and social isolation are terms often used interchangeably. While they are related, they are nonetheless distinctively different, especially for the individual affected. Loneliness is an individual's personal sense of lacking desired affection, intimacy, and social interaction with others. Although loneliness does have a social aspect, it is also subject to an individual's perceived emotional wellbeing and is more dependent on the quality of 
relationships than the quantity (Davidson, 2014). Whereas social isolation refers to a lack of contact with family or friends, community involvement, or access to services (Victor, 2012). There are many reasons for older adults becoming socially isolated, with some groups more likely to face this including the lower socio-economic groups, the widowed, the physically impaired, people with a sensory impairment and those with dementia and other mental health difficulties. Often these groups are within the very oldest of society (Age UK, 2010). A UK survey in 2012 on older age, found women self-reported the highest rates of "perceived loneliness" (Victor and Yang, 2012). Social isolation is a well-known and established issue amongst older adults, and evidence indicates the detrimental effect that it can have on health and wellbeing (Dickens et al., 2011). Becoming a carer also increases the risk of loneliness (Cann and Jopling, 2011). It is estimated that among those aged over 65, 12 per cent feel isolated, and with an increasing ageing population and continued family dispersion; this figure is likely to increase (SCIE, 2012). Those aged 80 and over are considerably more likely to report being lonely than any other age groups (Beaumont, 2013). Social isolation often leads to loneliness, dissatisfaction with life, and concurrent depressive episodes, of which suicidal ideation can be a key feature (Swami et al., 2007). Loneliness is proven to have a direct link to suicide for older adults (Griffin, 2010, Mellqvist Fässberg et al., 2012). Age UK (2010) notes that there have been many attempts to address this area of need with local and national policy, but very few interventions have been evaluated to provide an evidence base of success.

\section{Alcohol}

Contrary to public opinion, just 1 per cent of 16-24 year olds questioned had drunk every day in the past week, compared to 13 per cent of those surveyed aged 65 or over (Alcohol Concern, 2013). In the past five years there has been a 62 per cent increase in alcoholrelated hospital admissions for the over 65s (McVeigh, 2013). Surprisingly, the number of deaths in the UK linked to alcohol, more than doubled between 1992 and 2008, from 4,023 to 9,031, with the highest death rates found in men aged 55-74 (Royal College of Psychiatrists, 2011). According to Wadd et al. (2011, p. 3), "evidence suggests that the UK may be on the cusp of an epidemic of alcohol related harm amongst older adults". Increased risk of memory loss, dementia, and depression are among the mental health issues experienced by older drinkers (Livingston and Galvani, 2012), all of which are predictors of suicide in this population ( $O^{\prime}$ Connell et al., 2004). Alcohol abuse without question increases the risk of suicide among older adult populations (Fiske et al., 2009). Waern (2003) found a history of alcohol dependence or misuse was observed in 35 per cent of the elderly men who died by suicide, and in 18 per cent of the women. This figure appears to be backed by the Alcohol Concern Organisation which reports alcohol as being present in one in three suicides by older adults (Edwards, 2013). Sadly, older adults with alcohol dependency have historically been a marginalised group, whose particular needs have not been well met with only three per cent actively involved in treatment (Drugscope, 2014). This is even though there is strong evidence that older adults often respond and adhere to treatment better than younger people, especially if they are tailored to their needs (Wadd et al., 2011).

\section{Inequality}

A national survey of 1,600 health service managers found they regarded older adults, and those with mental health difficulties, as the most neglected groups using services, and those which had benefitted least from National Health Service (NHS) reforms (Centre for Policy on 
Ageing (CPA), 2009). Ageist attitudes towards older adults has compounded this inequality, driven by stigma and an unhealthy assumption that mental health problems are an inevitable part of the ageing process (Mental Health Foundation, 2009). The Healthcare Commission (2009) highlighted that older adults were not having access to the same services in NHS trusts as younger people when at risk of suicide, in particular out of hours services, crisis response, and psychological therapies. In 2007 a survey reported that of all the Crisis Response and Home Treatment (CRHT) teams available only 9 per cent supported people with dementia (Cooper et al., 2007). Crisis assessment and home treatment options for over 65s are an important development in eradicating age discrimination within mental health services (Royal College of Psychiatrists, 2009). Pinner et al. (2011) believe that the obvious lack of provision of CRHT to older adults is a clear breach of the Equality Act (c.15) (2010). In the UK, there is limited treatment and interventions for older adults with mental health problems who may be at risk of suicide, particularly psychological therapies (Manthorpe and lliffe, 2011). Conwell and Duberstein (2001) suggest that attitudinal studies indicate that it is considered more acceptable for older adults to end their life by suicide than their younger counterparts, and this attitude restricts resources being dedicated to the suicide prevention of older adults. Older adults are often devalued by society and even considered second class citizens, as they are considered non-productive and dependant (Beeston, 2006). Fischer et al. (2003) note that primary care providers were almost nine times more likely to document information on suicide risk, and three times more likely to refer to a mental health specialist for young adult patients than older patients.

\section{Suicide prevention}

There have been some improvements for older adults since the national suicide prevention strategy for England was launched, but many interventions are localised and not national, as was hoped (National Institute for Mental Health in England (NIMHE), 2007). Targets included the promotion of the mental health needs of older adults, providing information about social support groups and activities to reduce social isolation, and researching alcohol dependency; all of which are recognised triggers to suicide (Her Majesty's Government and Department of Health, 2002). There is of course no one single reason for an act of suicide, but a "diversity of difficulties". Interventions are required in all associated risk factors, if prevention is to be successful (Minayo and Cavalcante, 2010). Management of suicide should not be determined by age. However by the very fact that older adults statistically tend to be more determined to complete an act of suicide there is an urgency to consider prevention interventions (Conwell, 2007). Preventing suicide in England: a crossgovernment outcomes strategy to save lives (Department of Health, 2012a) suggests that in order to bring the number of older adult suicides down specialist assessment, and multidisciplinary agency management is required, particularly when addressing stigma and social isolation (Department of Health, 2014b). One area of obvious neglect with regards suicide prevention and research is BME groups where there are an increasing number of suicides, in particular male migrants from the Indian sub-continent and female migrants from Africa and China (Shah, 2013). Very little suicide prevention policy or practice can be found across the UK, which to older adults, particularly those from BME groups, even though what little evidence that does exist, places these groups as high risk. Preventing suicide in England: One year on, all first annual reports on the cross-government outcomes strategy to save lives (Department of Health, 2014b), Department of Health Social Services and Public Safety 
(2014) for Northern Ireland and Suicide Prevention Strategy 2013-2016 (Scottish

Government, 2013) either make no mention of older adults or at best a tokenistic sentence. Much more is required if suicide prevention policy is going to address this growing and vulnerable group.

\section{Conclusion}

This paper provides evidence that the ageing process can often be accompanied by a comorbidities which raise support needs. These are not always directly connected with being older, as which poverty or isolation. They can however, exacerbate the situation, leading to a complex and diverse set of challenges, and in turn an increased risk of suicide. There is no easy answer to why there is evidence of a growing number of older adults deciding that suicide is there only option, and even fewer suggestions on how to manage this risk. But there is one certainty in that the entry of the "baby boom" generation into retirement will mean this is an issue that is not going to go away any time soon. This demographic surge is likely to place additional pressures on already under resourced and undervalued statutory and non-statutory services. For many years now older adults and the services that support them have been undervalued. For example, even the strongest advocates of Older People's Mental Health services understand they are the "Cinderella of the Cinderella services" (Personal Social Services Research Unit (PSSRU), 2004). This is unfortunate as even though it has been evidenced that older adult services are under resourced, and under established, they continue to generate good treatment outcomes (Beecham et al., 2008). Another area of concern highlighted in this paper is age discrimination. Even when it comes to someone taking their life it would appear that policy makers consider the needs of younger adults more than those of their older counterparts. This is evidenced by the lack of mention of older adults in all of the current UK suicide prevention policies. The UK Home Secretary, Theresa May, set out plans for a blanket ban on age discrimination in health services in response to fears that changes to the Equality Act (c.15) (2010) were being side-lined (Wintour, 2012). These announced: "Ministers will promise that all people, regardless of age, will receive personal, fair and diverse services, based on their individual needs and not their age" (Wintour, 2012), guided by the Department of Health (2012b) document implementing the ban. This laid down expectations that services were to be targeted at those in need, regardless of age, and stated, "assessment should not be guided by chronological age unless chronological age is "genuinely relevant" to the decision and is objectively reasonable and proportionate" (Department of Health, 2012b; Age UK, 2012). The inertia to change and the failure for policy and commissioning to respect the needs of older adults can only be considered as discrimination (Anderson et al., 2009; Pinner et al., 2011).

This paper indicates a lack of research to explore the psychological, social and biological aspects of ageing, and their relationship to recent increasing rates of suicide of older adults. Commissioning studies could positively impact on older adult suicide statistics and further develop suicide prevention services within the UK. Future studies could perhaps include research through social enquiry, such as interviews and case studies to closely could explore the lived experience of this cohort and consider why suicide is on the increase. 


\section{References}

Age Concern (2008), Older People in the UK: Key Facts Leaflet, Age Concern, London.

Age UK (2010), Loneliness and Isolation Evidence Review, Age UK, London.

Age UK (2012), Briefing: Ban on Age Discrimination in Services, Age UK, London, available at: www.ageuk.org. uk/documents/en-gb/for-professionals/equality-and-

humanrights/age_disc_reg_oct_2012.pdf?dtrk=true

(accessed 6 December 2014).

Age UK (2014), Reducing Fuel Poverty - A Scourge for Older People: A Time for Renewed Vision and Ambition, Age UK, London.

Alcohol Concern (2013), "Statistics on alcohol", available at:

www.alcoholconcern.org.uk/wp-content/ uploads/2014/09/Summary-of-alcohol-

statistics.pdf (accessed 6 December 2014).

Aldridge, H., Bushe, S., Kenway, P., Maclnnes, T. and Tinson, A. (2013), London's Poverty Profile 2013, Trust for London and New Policy Institute, London.

Almeida, O.P., Pirkis, J., Kerse, N., Sim, M., Flicker, L., Snowdon, J., Draper, B., Byrne, G., Goldney, R. and Lautenschlager, N.T. (2012), "Randomized trial to reduce the prevalence of depression and self-harm behavior in older primary care patients", Annals of Family Medicine, Vol. 10 No. 4, pp. 347-56, available at:

www.ncbi.nlm.nih.gov/pmc/articles/PMC3392294/pdf/0100347.pdf (accessed 14 December 2014).

Anderson, D., Banerjee, S., Barker, A., Connelly, P., Junaid, O., Series, H. and Seymour, J. (2009), The Need to Tackle Age Discrimination inMental Health: A Compendiumof Evidence, Royal College of Psychiatrists, London.

Bayliss, J. and Sly, F. (2010), Ageing Across the UK, Office for National Statistics, Newport.

Beaumont, J. (2013), Measuring National Well-being - Older People and Loneliness, 2013, Office for National Statistics, London, available at:

www.ons.gov.uk/ons/dcp171766_304939.pdf (accessed 11 December 2014).

Beecham, J., Knapp, M., Fernández, J.L., Huxley, P., Mangalore, R., McCrone, P., Snell, T., Winter, B. and Wittenberg, R. (2008), Age Discrimination in Mental Health Services (PSSRU Discussion Paper, 2336), Personal Social Services Research Unit, Kent, London and Manchester, available at: www.pssru.ac.uk/pdf/dp2536.pdf (accessed 1 December 2014).

Beeston, D. (2006), Older People and Suicide, Centre for Ageing and Mental Health, Staffordshire University/Care Services Improvement Partnership, Staffordshire.

Bruce, M.L., Ten Have, T.R., Reynolds, C.F., Katz, I.I., Schulberg, H.C.,Mulsant, B.H., Brown, G.K.,McAvay, G.J., Pearson, J.L. and Alexopoulos, G.S. (2004), "Reducing suicidal ideation 
and depressive symptoms in depressed older primary care patients: a randomized controlled trial", The Journal of American Medical Association, Vol. 291 No. 9, pp. 1081-91.

Cann, P. and Jopling, K. (2011), The Challenge. Safeguarding the Convoy: A Call to Action from the Campaign to End Loneliness, Age UK, Oxfordshire.

Cattell, H. (2000), "Suicide in the elderly", Advances in Psychiatric Treatment, Vol. 6 No. 2, pp. 102-8.

Centre for Policy on Ageing (CPA) (2009), Ageism and Age Discrimination in Primary and Community Health Care in the United Kingdom: A Review from the Literature, Centre for Policy on Ageing, London.

Conwell, Y. (2007), "Suicide in older adults: management and prevention", Psychiatric Times, Vol. 24 No. 1, pp. 1-2.

Conwell, Y. and Duberstein, P.R. (2001), "Suicide in elders", Annals of the New York Academy of Sciences, Vol. 932 No. 1, pp. 132-50.

Cooper, C., Regan, C., Tandy, A.R., Johnson, S. and Livingston, G. (2007), "Acute mental health care for older people by crisis resolution teams in England", International Journal of Geriatric Psychiatry, Vol. 22 No. 3, pp. 263-5.

Davidson, S. (2014), Evidence Review: Loneliness in Later Life, Age UK, London.

Department for Work and Pensions (2013), Framework for the Analysis of Future Pension Incomes, DWP, London.

Department of Energy \& Climate Change (2013), Fuel Poverty Report - Updated August 2013, Department of Energy and Climate Change, London.

Department of Health (2012a), Preventing Suicide in England: A Cross-Government Outcomes Strategy to Save Lives, DH, London.

Department of Health (2012b), Implementing a Ban on Age Discrimination in the NHS Making Effective, Appropriate Decisions, DH, London.

Department of Health (2014a), Comorbidities: A Framework of Principles for System-Wide Action, Department of Health, NHS England and Public Health England, London, available at: www.gov.uk/government/uploads/system/uploads/attachment data/file/307143/Comorbi dities framework.pdf (accessed 29 November 2014).

Department of Health (2014b), Preventing Suicide in England: One Year on. First Annual Report on the Cross-Government Outcomes Strategy to Save Lives, DH, London. 
Department of Health Social Services and Public Safety (2014), Development of the New Suicide Prevention Strategy for Northern Ireland - Pre-consultation Engagement Summary Report, DHSSPS, Belfast.

Dickens, A., Richards, S., Greaves, C. and Campbell, J. (2011), "Interventions targeting social isolation in older people: a systematic review", Bio Medical Central: Public Health, Vol. 11 No. 647, pp. 1-22, available at: www.biomedcentral.com/content/pdf/1471-2458-11647.pdf (accessed 14 December 2014).

Drugscope (2014), It's About Time: Tackling Substance Misuse in Older People, Drugscope, London, available at:

www.drugscope.org.uk/Resources/Drugscope/Documents/PDF/Policy/ItsAboutTimeWeb.pd f (accessed 14 December 2014).

Dunnell, K. (2008), Diversity and Different Experiences in the UK: National Statistician's Annual Article on Society, Office of National Statistics, London.

Edwards, K. (2013), Working with Dual Diagnosis in Older Adults, South Essex Partnership University NHS Foundation Trust (SEPT), Essex, available at:

www.beds.ac.uk/_data/assets/pdf_file/0010/225865/Presentation-Kim-Edwards.pdf (accessed 7 December 2014).

Erlangsen, A., Zarit, S.H. and Conwell, Y. (2008), "Hospital-diagnosed dementia and suicide: a longitudinal study using prospective, nationwide register data", The American Journal of Geriatric Psychiatry, Vol. 16 No. 3, pp. 220-8.

Equality Act (c.15) (2010), "London: The Stationery Office", available at: www.legislation.gov.uk/ukpga/2010/15/pdfs/ukpga_20100015_en.pdf (accessed 14 December 2014).

Fischer, L.R., Feifei, W., Solberg, L.I., Rush, W.A. and Heinrich, L. (2003), "Treatment of elderly and other adult patients for depression in primary care", Journal of the American Geriatrics Society, Vol. 51 No. 11, pp. 1554-62.

Fiske, A., Loebach Wetherell, J. and Gatz, M. (2009), "Depression in older adults", Annual Review Clinical Psychology, Vol. 5, pp. 363-89, available at:

www.ncbi.nIm.nih.gov/pmc/articles/PMC2852580/pdf/ nihms-192082.pdf (accessed 7 December 2014).

Gavrielatos, G., Komitopoulos, N., Kanellos, P., Varsamis, E. and Kogeorgos, J. (2006), "Suicidal attempts by prescription drug overdose in the elderly: a study of 44 cases", Neuropsychiatric Disease and Treatment, Vol. 2 No. 3, pp. 359-63, available at: www.ncbi.nlm.nih.gov/pmc/articles/PMC2671820/pdf/ndt-2-359.pdf (accessed 14 December 2014). 
Graham, C.C., Campion, J., Kaiser, P. and Edwards, K. (2011), Management of Depression in Older People: Why this is Important in Primary Care, National Mental Health Development Unit, London.

Griffin, J. (2010), The Lonely Society, The Mental Health Foundation, London.

Hawton, K. and Harriss, L. (2006), "Deliberate self-harm in people aged 60 years and over: characteristics and outcome of a 20 year cohort study", International Journal of Geriatric Psychiatry, Vol. 21 No. 6, pp. 572-81, available at:

www.ncbi.nlm.nih.gov/pubmed/16645937 (accessed 14 December 2014).

Healthcare Commission (2009), Equality in Later Life: A National Study of Older People's Mental Health Services, Healthcare Commission, London.

Help the Aged (2004), Beating the Blues, Help the Aged, London.

Her Majesty's Government and Department of Health (2002), National Suicide Prevention Strategy for England, DH, London.

International Federation of Social Workers (2012), "Ageing and older adults", IFSW, available at: http://ifsw.org/policies/ageing-and-older-adults/ (accessed 6 December 2014).

Kennedy, S. (2013), Winter Fuel Payments Update, House of Commons, London, available at: www.parliament.uk/briefing-papers/sn06019.pdf (accessed 7 December, 2004).

Laidlaw, K., Davidson, K.M., Toner, H., Jackson, G., Clark, S., Law, J., Howley, M., Bowie, G., Connery, H. and Cross, S. (2008), "A randomised controlled trial of cognitive behaviour therapy versus treatment as usual in the treatment of mild to moderate late life depression", International Journal of Geriatric Psychiatry, Vol. 23 No. 8, pp. 843-50, available at: www.ncbi.nlm.nih.gov/pubmed/18311844 (accessed 12 December 2014).

Livingston, W. and Galvani, S. (2012), Older People \& Alcohol - Essential Information for Social Workers. A BASW Pocket Guide, British Association of Social Workers, Birmingham.

McVeigh, T. (2013), "Older people are abusing alcohol more than the young", The Observer, 2 June, available at: www.theguardian.com/society/2013/jun/02/older-people-abusingalcohol (accessed 14 December 2014).

Manthorpe, J. and Iliffe, S. (2010), "Suicide in later life: public health and practitioner perspectives", International Journal of Geriatric Psychiatry, Vol. 25 No. 12, pp. 1230-8.

Manthorpe, J. and Iliffe, S. (2011), "Social work with older people - reducing suicide risk: a critical review of practice and prevention", British Journal of Social Work, Vol. 41 No. 1, pp. 131-47.

Mellqvist Fässberg, M., van Orden, K.A., Duberstein, P., Erlangsen, A., Lapierre, S., Bodner, E., Canetto, S.S., De Leo, D., Szanto, K. andWaern,M. (2012), “A systematic reviewof social 
factors and suicidal behavior in older adulthood", International Journal of Environmental Research and Public Health, Vol. 9 No. 3, pp. 722-45.

Mental Health Foundation (2009) All Things Being Equal: Age Equality in Mental Health Care for Older People in England, Mental Health Foundation, London.

Mental Health Foundation (2014), "Suicide", available at: www.mentalhealth.org.uk/helpinformation/mental-health-a-z/s/suicide/ (accessed 14 December 2014).

Minayo, M.C.S. and Cavalcante, F.G. (2010), Suicide in Elderly People: A Literature Review. Rev SaÚde Pública, Vol. 44 No. 4, pp. 1-7, available at:

www.scielosp.org/pdf/rsp/v44n4/en_20.pdf (accessed 14 December 2014).

Mitchell, R. (2008), Kill Me If I Have Alzheimer's: Physician-Assisted Suicide and Dementia, Social Science Research Network, Seattle University School of Law, Seattle, WA, available at: http://papers.ssrn.com/sol3/papers.cfm?abstract_id=1266948 (accessed 29 November 2014).

Murphy, E., Kapur, N., Webb, R., Purandare, N., Hawton, K., Bergen, H., Waters, K. and Cooper, J. (2012), "Risk factors for repetition and suicide following self-harm in older adults: multicentre cohort study", British Journal of Psychiatry, Vol. 200 No. 5, pp. 399-404, available at:

http://bjp.rcpsych.org/content/200/5/399.abstract?ijkey=32a77a4a13e10bfdb8ca24ab84e6 17c10ea60be7\&keytype2=tf_ipsecsha (accessed 14 December 2014).

National Institute for Mental Health in England (2005), Facts for Champions, Department of Health, London.

National Institute for Health and Clinical Excellence (NICE) (2004), Depression: Management of Depression in Primary and Secondary Care, Clinical Guideline 23, NICE, London.

National Institute for Mental Health in England (NIMHE) (2007), National Suicide Prevention Strategy for England: Annual Report on Progress, NIMHE, Leeds.

Nugent, H. (2012), "Suicide on the rise among older men", The Guardian, 15 July, available at:www.theguardian.com/society/2012/jul/15/suicide-rise-older-men (accessed 14 December 2014).

O'Connell, H., Chin, A.V., Cunningham, C. and Lawlor, B.A. (2004), "Recent developments: suicide in older people", BMJ: British Medical Journal (International Edition), Vol. 329 No. 7471, pp. 895-9.

O’Dwyer, S.T., Moyle, W., Zimmer-Gembeck, M. and De Leo, D. (2013), "Suicidal ideation in family carers of people with dementia: a pilot study", International Journal of Geriatric Psychiatry, Vol. 28 No. 11 , pp. 1182-8. 
Office for National Statistics (2012), Suicide Rates in the United Kingdom, 2006 to 2010, ONS, London.

Office for National Statistics (2013), Suicides in the United Kingdom, 2011, ONS, London.

Office of the First Minister and Deputy First Minister (2013), A Profile of Older People in Northern Ireland - 2013 Update, OFMdFM, Belfast.

Palmer, G. (2010), "What the indicators show: older people: the poverty site", available at: www.poverty.org.uk/summary/older.htm (accessed 7 December 2014).

Parekh, A., Maclnnes, T. and Kenway, P. (2010), Monitoring Poverty and Social Exclusion 2010, Joseph Rowntree Foundation, York, available at:

www.jrf.org.uk/sites/files/irf/poverty-social-exclusion-2010-full.pdf (accessed 1 December 2014).

Personal Social Services Research Unit (PSSRU) (2004), Mental Health in Old Age Bulletin, Issue 6, PSSRU, Manchester, available at: www.pssru.ac.uk/pdf/MCpdfs/DPM121.pdf (accessed 12 December 2014).

Pinner, G., Hillam, J., Branton, T. and Ramakrishnan, A. (2011), In-Patient Care for Older People Within Mental Health Services, Royal College of Psychiatrists, London, available: www.rcpsych.ac.uk/pdf/FR_OA_1_forweb.pdf (accessed 14 December 2014).

Powell, R. (2014), "Is preventive suicide a rational response to a presymptomatic diagnosis of dementia?", Journal of Medical Ethics, Vol. 40 No. 8, pp. 511-12.

Purandare, N., Oude Voshaar, R.C., Rodway, C., Bickley, H., Burns, A. and Kapur, N. (2009), "Suicide in dementia: 9-year national clinical survey in England and Wales", The British Journal of Psychiatry, Vol. 194 No. 2, pp. 175-80.

Royal College of Nursing (2012), Health Inequalities and the Social Determinants of Health, RCN, London, available at:

www.rcn.org.uk/_data/assets/pdf_file/0007/438838/01.12_Health_inequalities_and_the_ social_determinants_of_health.pdf (accessed 14 December 2014).

Royal College of Psychiatrists (2009), Age Discrimination in Mental Health Services: Making Equality a Reality, Royal College of Psychiatrists' Position Statement, Royal College of Psychiatrists, London, available at: www.rcpsych.ac.uk/pdf/PS02_2009x.pdf (accessed 14 December 2014).

Royal College of Psychiatrists (2011), Our invisible addicts: First report of the Older Persons' Substance Misuse, Working Group of the Royal College of Psychiatrists, Report No. CR165, $\mathrm{RCP}$, London.

Samaritans (2015), "Suicide Statistics Report 2015", available at: www.samaritans.org/sites/default/files/kcfinder/branches/branch96/files/Suicide_statistics _report_2015.pdf (accessed 23 August 2015). 
SCIE (2012), At a Glance Briefing 60: Preventing Loneliness and Social Isolation Among Older People, Social Care Institute for Excellence, London.

Scogin, F. (2009), Depression and Suicide in Older Adults Resource Guide, American Psychological Association, Washington, DC, available at: www.apa.org/pi/aging/resources/guides/depression.aspx (accessed 1 December 2014).

Scottish Government (2013), Suicide Prevention Strategy 2013-2016, Scottish Government, Edinburgh.

Shah, A. (2013), "Suicide in older black and minority ethnic people: a cause for concern", Old Age Psychiatrist, No. 57, pp. 1-5, available at:

www.rcpsych.ac.uk/pdf/draftBMEelderlysuicideeditorialforoldagepsychiatrist\%20ed\%202.p df (accessed 14 December 2014).

Sontheimer, D. (2008), "Suicide by advance directive?", Journal of Medical Ethics, Vol. 34 No. 9, pp. 13-9.

Spector, J. and Tampi, R. (2005), “Caregiver depression”, Annals of Long-Term Care: Clinical Care and Aging, Vol. 13 No. 4, pp. 34-40.

Spijker, J. and MacInnes, J. (2013), “Population ageing: the time bomb that isn't?”, British Medical Journal, Vol. 347 No. f6598, pp. 20-2.

Swami, V., Chamorro-Premuzic, T., Sinniah, D., Maniam, T., Kannan, K., Stanistreet, D. and Furnham, A. (2007), "General health mediates the relationship between loneliness, life satisfaction and depression", Social Psychiatry and Psychiatric Epidemiology, Vol. 42 No. 2, pp. 161-6.

Szanto, K., Prigerson, H. and Reynolds, C.F. III, (2001), "Suicide in the elderly", Clinical Neuroscience Research, Vol. 1 No. 5, pp. 366-76.

Turvey, C., Conwell, Y., Jones, M., Phillips, C., Simonsick, E., Pearson, J. et al. (2002), "Risk factors for late-life suicide: a prospective, community-based study", The American Journal of Geriatric Psychiatry, Vol. 10 No. 4, pp. 398-406.

Victor, C. (2012), "What do you expect at your age? Loneliness and old age", presentation for Age UK, April 2013, available at:

www.campaigntoendloneliness.org/wpcontent/uploads/downloads/2012/07/VictorLoneliness-Plenary-July2012.pdf (accessed 1 December 2014).

Victor, C. and Yang, K. (2012), "The prevalence of loneliness among adults: a case study of the United Kingdom", The Journal of Psychology: Interdisciplinary and Applied, Vol. 146 Nos 1-2, pp. 85-104. 
Wadd, S., Lapworth, K., Sullivan, M., Forrester, D. and Galvani, S. (2011), "Working with older drinkers - Tilda Goldberg Centre/University of Bedfordshire", available at:

http://alcoholresearchuk.org/downloads/finalReports/FinalReport_0085 (accessed 14 December 2014).

Waern, M. (2003), "Alcohol dependence and misuse in elderly suicides", Alcohol and Alcoholism, Vol. 38 No. 3, pp. 249-54.

Wintour, P. (2012), "Theresa May announces blanket ban on age discrimination of patients", The Guardian, 11 June, available at: www.guardian.co.uk/society/2012/jun/11/theresamay-patient-age-discrimination-ban (accessed 7 December 2014).

World Health Organization (1998), Health Promotion Glossary, WHO, Geneva, available at: www.who.int/healthpromotion/about/HPR\%20Glossary\%201998.pdf (accessed 1 December 2014).

World Health Organization (2007), Mental Health: WHO Urges More Investments, Services for Mental Health, WHO, Geneva, available at:

www.who.int/mediacentre/news/releases/2007/pr45/en/ (accessed 1 December 2014).

\section{Further reading}

Conwell, Y. (2001), "Suicide in later life: a review and recommendations for prevention", Suicide and Life Threatening Behavior, Vol. 31 No. 1, pp. 32-47.

Department of Health (1999a), Saving Lives: Our Healthier Nation, DH, London.

Department of Health (1999b), National Service framework for Mental Health, DH, London. 